Gut, 1975, 16, 277-284

\title{
Electrical potential difference, sodium absorption and potassium secretion by the human rectum during carbenoxolone therapy
}

\author{
A. M. TOMKINS AND C. J. EDMONDS1
}

From the University College Hospital, London, and Clinical Research Centre, Northwick Park Hospital, Harrow, Middx

SUMMARY The transmucosal electrical potential difference (pd) and the sodium and potassium net fluxes were measured in the rectum of subjects taking carbenoxolone. There was a rise in transmucosal pd persisting throughout treatment in all subjects which was accompanied by an increase in sodium absorption and potassium secretion. Comparison of the pd changes produced by carbenoxolone with those due to the mineralocorticoid 9- $a$-fluorocortisol showed that carbenoxolone had about $1 / 1000$ th the potency on a weight basis and the two drugs appeared to be additive in their effects. Topical instillation of carbenoxolone into the rectum produced an elevation of pd which persisted for three days. Amiloride and bendrofluazide did not interfere with these actions of carbenoxolone but spironolactone abolished them. One patient who developed fluid retention and hypokalaemia had a rectal pd similar to that of the other patients who had no side effects.

Carbenoxolone sodium is of proven value in the treatment of gastric ulcer (Doll, Hill, Hutton, and Underwood, 1962) but its use is sometimes complicated by the development of side effects, particularly fluid retention, hypokalaemia, and hypertension. These mineralocorticoid-like effects might be anticipated as carbenoxolone is a derivative of glycyrrhizic acid, a constituent of liquorice roots, and liquorice has been known for some time to have mineralocorticoid properties (Borst, ten Holt, de Vries, and Molhuysen, 1953). The mechanism of the production of the hypokalaemia has not been fully explained since it has usually been difficult to demonstrate much increase in potassium loss in the urine (Baron and Nabarro, 1968; Wynn, 1968; MacKay, 1968). The bowel is a possible source of the potassium loss, for under stimulation by mineralocorticoids potassium excretion by this route is increased (Shields, Mulholland, and Elmslie, 1966; Edmonds, 1972). Mineralocorticoid effects on the bowel are demonstrable by measurement of the electrical pd across the mucosa, aldosterone, for example, producing a considerable rise in the pd within a few hours of its administration (Edmonds and Godfrey, 1970), and in a report on one patient Beevers (1973) noted that

${ }^{1}$ Correspondence to Dr C. J. Edmonds, Clinical Research Centre, Northwick Park Hospital. Harrow, Middx.

Received for publication 16 January 1975. the pd rose during carbenoxolone therapy. In the present paper, we describe the effects of carbenoxolone therapy on the rectal pd in patients with peptic ulcer and in normal volunteers together with the influence of various diuretics. We have also studied the effect of carbenoxolone on the sodium and potassium net fluxes using the dialysis method (Edmonds, 1971) and on the ions in faecal water.

\section{Methods}

PATIENTS AND NORMAL INDIVIDUALS

The principal studies were performed on nine patients with peptic ulcer (six had gastric ulcer and three had duodenal ulcer) and two normal individuals. Eight of these patients, aged 19-65 years, were otherwise healthy with no clinical or laboratory evidence of cardiac, renal, or hepatic disease, and blood pressure and serum electrolytes were all normal at the start of the study. Each patient was studied before, during, and after a six-week course of carbenoxolone sodium using $100 \mathrm{mg}$ three times daily for one week followed by $50 \mathrm{mg}$ three times daily for five weeks. All these individuals were outpatients and at each clinic attendance body weight, blood pressure, serum potassium, total body potassium $\left(\mathrm{K}^{40}\right)$, and transmucosal pd were recorded. A further patient was investigated (W.B., a 62-year- 
old man with a gastric ulcer) who developed fluid retention while taking carbenoxolone. He had been previously fit with normal exercise tolerance and at the initial physical examination chest radiographs and biochemical screening showed no abnormality. In the outpatient trial, he gained an undue amount of weight during the first week of carbenoxolone treatment and the drug was discontinued. In view of continuing peptic ulcer symptoms, he was admitted two weeks later and the trial of carbenoxolone was carried out during his inpatient stay.

Two healthy volunteers were also investigated while taking varying doses of carbenoxolone and intermittently bendrofluazide or spironolactone. They continued normal activities throughout the period of investigation.

\section{TRANSMUCOSAL ELECTRICAL PD}

The pd was measured using a probe electrode constructed from a perspex (lucite) tube which contained an $\mathrm{Ag}-\mathrm{AgCl}$ junction in contact with a short column of saline-agar ( $150 \mathrm{mmol} / \mathrm{l}-4 \%$ agar). The skin electrode, which was also constructed from perspex, contained a $\mathrm{Ag}-\mathrm{AgCl}$ junction and saline agar and was applied to a bleb produced by the intradermal injection of sterile isotonic sodium chloride solution (Archampong and Edmonds, 1972). The saline injection abolishes the skin potential so that the pd measured between the probe electrode applied to the mucosa and the skin electrode is equal to the transmucosal 'pd. The asymmetry pd of the electrode system was always checked before and after measurements and any necessary correction made. Measurements of pd were recorded on the mucosa at about 8 to $10 \mathrm{~cm}$ from the anus.

\section{FLUX MEASUREMENTS}

Dialysis tubes (Visking, diameter $0.5 \mathrm{~cm}$, length 8 $\mathrm{cm})$ mounted on rubber catheters and containing $1.6 \mathrm{ml}$ of solution were used. Full details of this method with its evaluation and calculations used to estimate flux rates have previously been described (Edmonds, 1971). The tubes were weighed before and after experiments to measure fluid absorption, the tube being first wiped clean of any adherent mucus or other fluid. Any tube showing evidence of faecal contamination was discarded. The tube was carried between weighings in a small impermeable plastic container. Preliminary trials showed that this procedure reduced evaporation to negligible levels. Measurements were made using a Mettler (Zürich) type $\mathrm{H} 16$ balance to the nearest milligram. One hour before beginning the experiment, the rectum was rinsed several times with saline $(150 \mathrm{mmol} / \mathrm{l} \mathrm{NaCl})$ until an entirely clean return was obtained. Two solutions freshly prepared from stock solutions were used: solution I, sodium $10 \mathrm{mmol} / \mathrm{l}$, potassium $30 \mathrm{mmol} / \mathrm{l}$, choline $110 \mathrm{mmol} / \mathrm{l}$; solution II, sodium $145 \mathrm{mmol} / \mathrm{l}$, potassium $5 \mathrm{mmol} / \mathrm{l}$. For both solutions the anion composition was chloride $120 \mathrm{mmol} / \mathrm{l}$ and

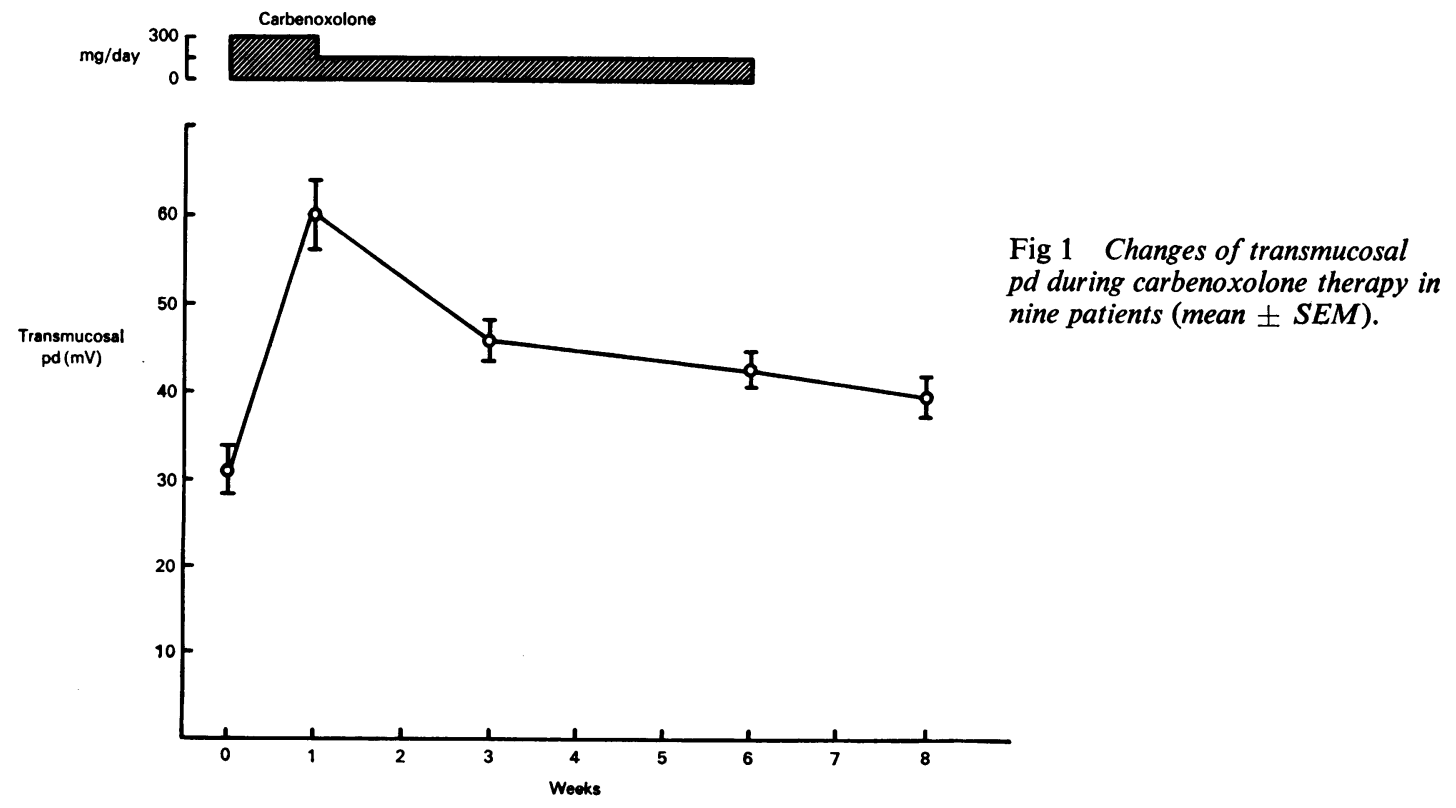




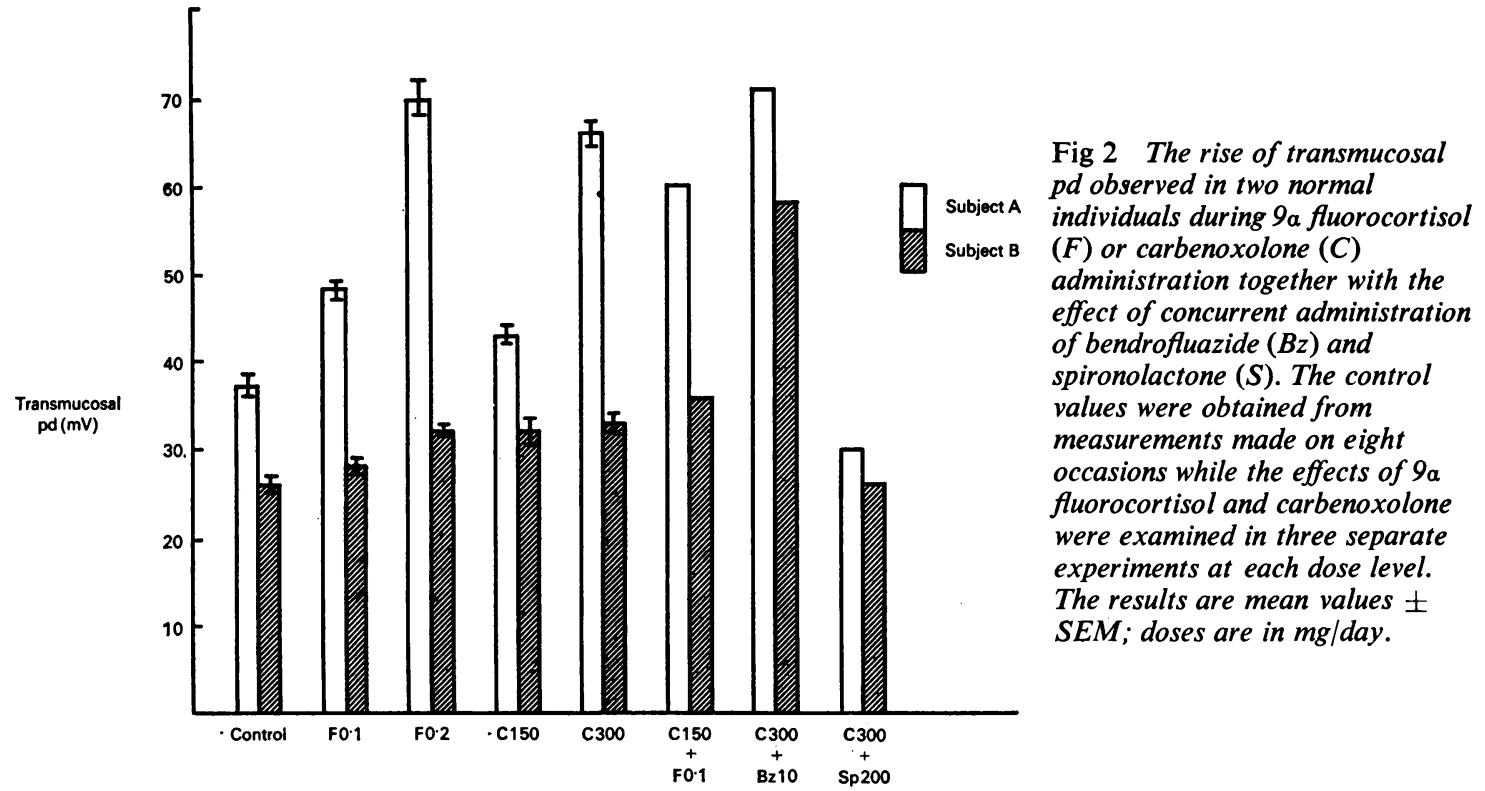

bicarbonate $30 \mathrm{mmol} / \mathrm{l}$. Sodium and potassium were measured by flame photometry and the composition of aliquots obtained before and after experiments was determined and used in the results.

\section{FAECAL ELECTROLYTES}

Specimens of faecal fluid were obtained by the patients swallowing (and subsequent recovery from the faeces) bags made from Visking tubing (8/32) previously filled with Rheomacrodex and then dried (Wrong, Metcalfe-Gibson, Morrison, $\mathrm{Ng}$, and Howard, 1965). Equilibration of faecal water, electrolytes, and intracapsular fluid occurs during passage through the bowel and the ionic concentrations in the intracapsular fluid reflect those of the faecal water.

\section{Results}

EFFECT OF CARBENOXOLONE ON

TRANSMUCOSAL PD

\section{Patients}

In the eight of our patients who had no significant disease apart from peptic ulcer, the transmucosal pd was observed to rise significantly $(P<0.01)$ by the end of the first week of carbenoxolone therapy (fig 1). The pd remained significantly $(P<0.05)$ elevated throughout the period of treatment although falling when the dose was changed at the end of the first week from $300 \mathrm{mg}$ daily to $150 \mathrm{mg}$ daily. The pd fell after stopping treatment. None of these patients developed overt oedema but one had a weight gain of $2.5 \mathrm{~kg}$ and three patients had an increase of more than $10 \mathrm{~mm} \mathrm{Hg}$ diastolic pressure. Significant hypokalaemia or fall in total body potassium did not occur.

\section{Normal individuals}

The transmucosal pd, measured on a number of different occasions before treatment began, showed a considerable difference between the two individuals but the measurements in each were consistent and the mean pd of both was within our established range for normals $(34 \pm 6 \mathrm{mV}$ SD from 24 normal individuals). Comparison of the response of $\mathrm{pd}$ to various treatment regimens was examined (fig 2). $9-\alpha$-Fluorocortisol, a potent mineralocorticoid, taken orally in doses of $0.1 \mathrm{mg}$ or $0.2 \mathrm{mg}$ daily for three days, produced a rise in $\mathrm{pd}$, the values shown being those found on the third day. It has been shown previously that the pd does not alter significantly if the drug is continued for a longer period (Edmonds and Richards, 1970). Carbenoxolone given for five days produced a rise in pd by the fifth day. With carbenoxolone $150 \mathrm{mg}$ daily there was significant elevation in subject $A(P<0.05)$, but, although pd rose in subject $B$, the change did not achieve significance. With carbenoxolone $300 \mathrm{mg}$ daily the increase in pd was significant $(<0.05)$ in both subjects, the rise being approximately equivalent to that produced by $0.2 \mathrm{mg}$ of $9-\alpha$-fluorocortisol. To see how carbenoxolone and 9- $\alpha$-fluorocortisol behaved when taken together, carbenoxolone $150 \mathrm{mg}$ daily was given 
for five days and 9- $\alpha$-fluorocortisol $0.1 \mathrm{mg}$ daily was added for the last three days. The elevation of pd when measured on the fifth day of carbenoxolone was similar to that observed when carbenoxolone $300 \mathrm{mg}$ daily or $9-\alpha$-fluorocortisol $0.2 \mathrm{mg}$ daily was given alone. The effects of the two substances as judged by rectal pd did therefore appear to be additive; there was no evidence of potentiation or antagonism.

The influence of the diuretics bendrofluazide and spironolactone on the carbenoxolone action was examined in the normal individuals, the diuretics being given over the last two days of a five-day course of carbenoxolone $300 \mathrm{mg}$ daily. Bendrofluazide, 10 mg daily, did not interfere with the rise in pd produced by carbenoxolone but when spironolactone $200 \mathrm{mg}$ daily was taken the pd was considerably reduced (fig 2), indicating that spironolactone prevented completely the increase of pd which otherwise occurs during carbenoxolone therapy. Both diuretics produced a diuresis and reversed the weight gain produced by carbenoxolone alone.

\section{Topical application}

In animal experiments, aldosterone has been shown to be effective in altering pd only when it is applied to the serosal surface and practically without action when in the lumen of the gut (Edmonds and Marriott, 1969). The effect of carbenoxolone applied directly to the mucosal side of the epithelium was examined in two normal individuals, carbenoxolone dissolved in $20 \mathrm{ml}$ of normal saline being given by rectal enema. In both subjects a rise in transmucosal pd evident within a few hours and the change persisted for three days (fig 3 ). The extent of the increase in pd was similar after both $5 \mathrm{mg}$ and $50 \mathrm{mg}$ doses but a dose of $0.5 \mathrm{mg}$ had little effect.

STUDIES IN A PATIENT DEVELOPING

CONSIDERABLE FLUID RETENTION

Following the administration of carbenoxolone there was an expected early rise in transmucosal pd (fig 4) similar to that seen in other patients. When bendrofluazide was administered there was a further increase in potential difference. A marked diuresis with considerable loss of urinary potassium also occurred. Amiloride, a distal tubular diuretic, not only caused less elevation of pd but was also less effective in promoting a diuresis. When amiloride was used alone, the pd gradually fell as weight rose and fluid retention recurred. On giving bendrofluazide again at about six weeks after beginning carbenoxolone, weight fell abruptly and pd rose markedly again. The changes suggest that the elevation of pd depended both on the presence of carbenoxolone and on endogenous aldosterone production. The latter decreased as fluid retention occurred and was stimulated as a result of the diureticinduced diuresis.

\section{EFFECT OF CARBENOXOLONE ON ABSORPTION AND SECRETION}

\section{Changes in electrolyte concentration in rectal dialysis tubes}

In normal untreated individuals changes in electrolyte concentrations occurred during exposure of both solutions I and II (fig 5), sodium concentration increasing slightly with solution $I$ and decreasing

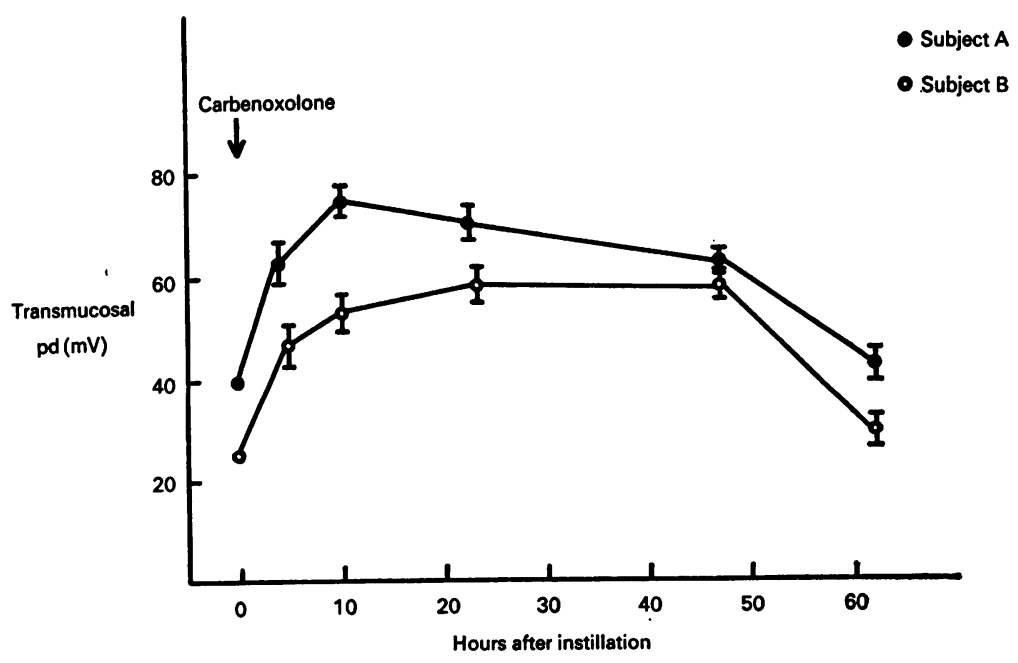

Fig 3 The rise of transmucosal pd following the topical application of $50 \mathrm{mg}$ of carbenoxolone to the rectal mucosa. Three separate experiments were conducted in each individual and the results are given as means $\pm S E M$. 


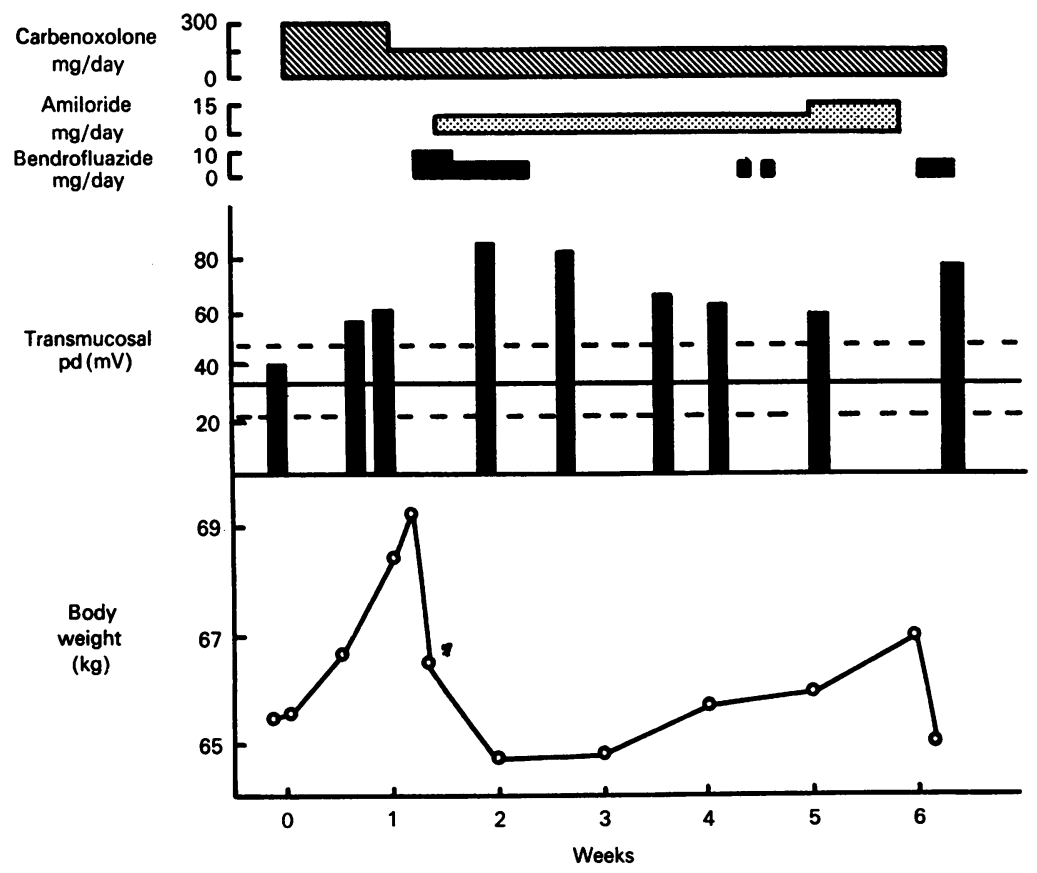

Fig 4 Changes of transmucosal pd observed in a patient who developed considerable oedema during carbenoxolone treatment. The horizontal continuous line and the interrupted lines show the mean $p d \pm 2 S D$ for a group of 24 normal individuals.

with solution II. After administration of carbenoxolone, $\mathbf{3 0 0} \mathrm{mg}$ daily for five days, sodium concentration now fell instead of increasing when solution I was used; this alteration was significant $(\mathbf{P}<0.01)$. With solution II the fall in sodium concentration was enhanced by carbenoxolone $(P<0.05)$. In the case of potassium, in the untreated individuals the concentrations rose both in solutions I and II. After carbenoxolone $300 \mathrm{mg}$ daily for five days, the increases in potassium concentration were significantly greater $(P<0.01)$ than in the untreated state.

The addition of bendrofluazide, $10 \mathrm{mg}$ daily, for the last two days of the carbenoxolone course did not appear to influence the action of carbenoxolone while spironolactone effectively antagonized it (fig 5).
Changes in electrolyte concentration of faecal fluids In normal individuals taking carbenoxolone $300 \mathrm{mg}$ daily for five days there were changes in electrolyte concentrations of the fluid within dialysis bags which had been swallowed on the third day of carbenoxolone therapy and recovered from the faeces on the fifth day. There was an increase in potassium concentration and decrease in sodium concentration (fig 6) but these changes did not achieve statistical significance.

\section{Sodium and potassium net fluxes}

Carbenoxolone produced changes in sodium absorption and potassium secretion when measured in normal individuals on the fifth day of a course of carbenoxolone $300 \mathrm{mg}$ daily (table). Using solution

\begin{tabular}{|c|c|c|c|c|c|c|c|}
\hline \multirow[t]{2}{*}{ Subject } & & \multicolumn{3}{|l|}{ Solution I } & \multicolumn{3}{|l|}{ Solution II } \\
\hline & & Control & Carbenoxolone & $\boldsymbol{P}$ & Control & Carbenoxolone & $\boldsymbol{P}$ \\
\hline $\begin{array}{l}A \\
B\end{array}$ & $\begin{array}{l}\text { Sodium } \\
\text { Potassium } \\
\text { Sodium } \\
\text { Potassium }\end{array}$ & $\begin{array}{r}+2.8 \pm 1.3 \\
+1.7 \pm 1.3 \\
-140 \cdot 1 \pm 12.2 \\
-10.1 \pm 3.2\end{array}$ & $\begin{array}{r}+12.9 \pm 2.8 \\
-6.1 \pm 3.7 \\
-84 \pm 8.2 \\
-44 \pm 5.4\end{array}$ & $\begin{array}{l}(<0.01) \\
(<0.05) \\
(<0.05) \\
(<0.01)\end{array}$ & $\begin{array}{rrr}+138.1 & \pm 17.1 \\
-33.3 & \pm 7.6 \\
+101 \cdot 1 & \pm 8.4 \\
-37.0 & 6.2\end{array}$ & $\begin{array}{r}+182.8 \pm 22.7 \\
-72.8 \pm 1.8 \\
+114.1 \pm 3.2 \\
-49.0 \pm 5.2\end{array}$ & $\begin{array}{l}(<0.05) \\
(<0.01) \\
(<0.05) \\
\text { (N.S.) }\end{array}$ \\
\hline
\end{tabular}

Table Effect of carbenoxolone, $300 \mathrm{mg}$ daily for five days, on sodium and potassium absorption and secretion rates in two normal individuals

${ }^{1}$ All results are in $\mathrm{nmol} / \mathrm{min} / \mathrm{cm}^{2}$ based on the surface area of the tube and given as mean \pm SEM. Four experiments in each individual and with each solution were carried out. Initial sodium concentration for solution I was 10 and for solution II, $145 \mathrm{mmol} / 1$; for potassium the initial concentrations were 30 and $5 \mathrm{mmol} / 1$ respectively. Absorption is given as + ve; secretion - ve. 


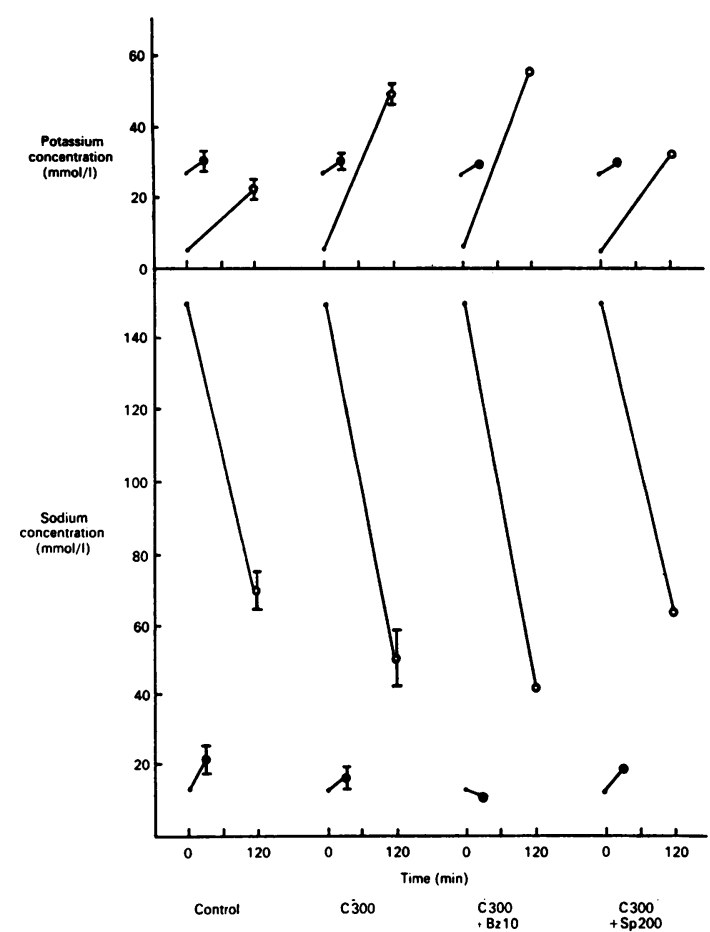

Fig 5 Changes in sodium and potassium concentrations of solutions $I(\Theta, 30$ min exposure $)$ and $I I(\bigcirc, 120$ min exposure) during exposure to the rectal mucosa. The results illistrated were from one of the normal individuals obtained from four separate experiments and given as means $\pm S E M$. The effects of addition of bendrofluazide and spironolactone were each studied on two occasions and the mean result is shown.

I there were increases in sodium absorption and potassium secretion which were significant in both individuals. Similar results were obtained using solution II with a significant increase in sodium absorption in both individuals and a significant increase in potassium secretion in one.

\section{Discussion}

The mucosal epithelium of the distal colon and rectum is responsible for active transport of sodium whereby ions are moved from lumen to blood against an ionic concentration gradient (Edmonds, 1971). This active transfer of sodium ions appears to be largely responsible for the observed transmucosal pd (Cooperstein and Hogben, 1959). Associated with the increase in sodium absorption and in potassium secretion produced by mineralocorticoids, such as aldosterone and $9-\alpha$-fluorocortisol, is a marked increase in the pd (Edmonds and Godfrey, 1970;

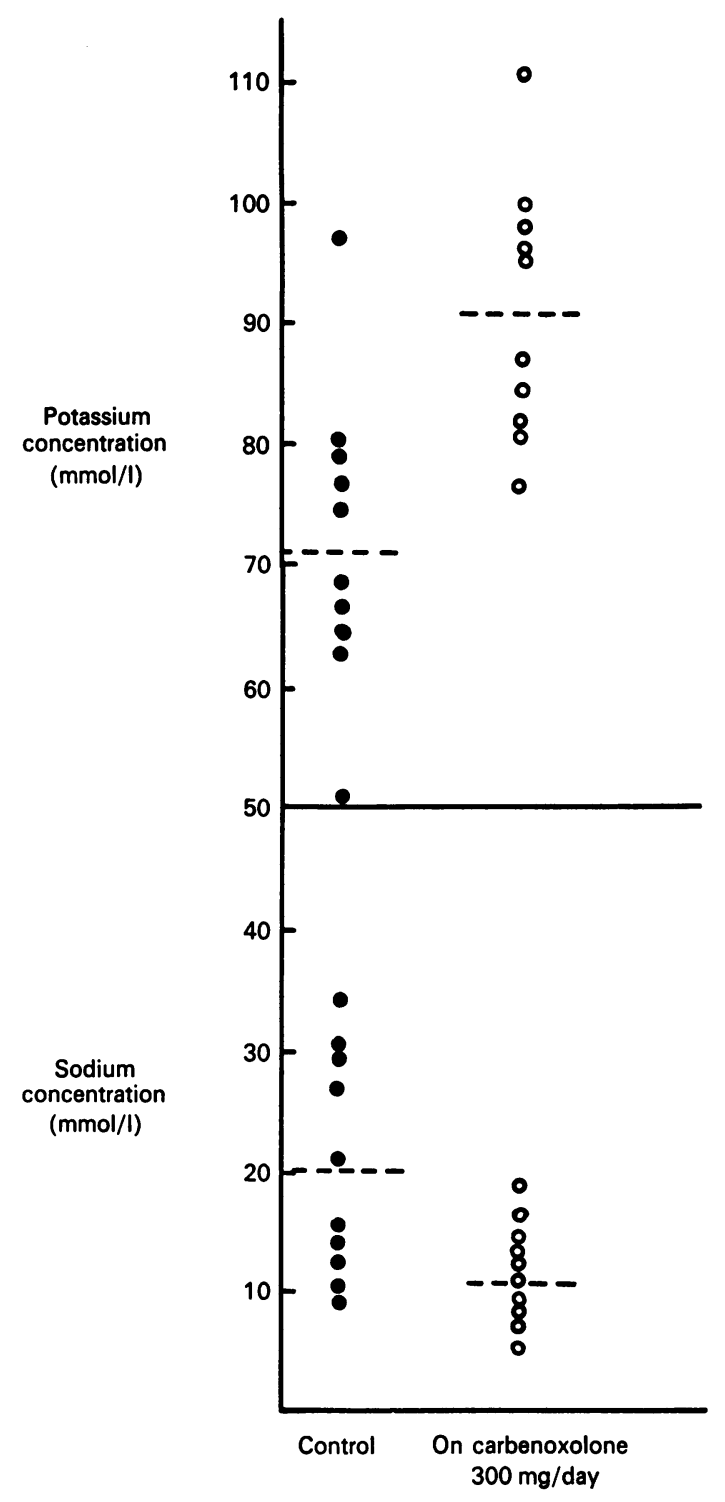

Fig 6 Changes in sodium and potassium concentrations of electrolyte solution within swallowed dialysis bags in two normal individuals during carbenoxolone therapy.

Edmonds, 1972; Efstratopoulos, Peart, and Wilson, 1974) so that rectal pd can be a simple index of mineralocorticoid activity.

Carbenoxolone sodium is synthesized from glycyrrhizic acid, one of the constituents of liquorice. Bothliquoriceand carbenoxolone can produce effects-fluid retention and hypokalaemia-similar to those occurring with high doses of mineralocorticoids. The present study showed that the action of 
carbenoxolone on the bowel was similar to that of mineralocorticoids like aldosterone. The rise in $\mathrm{pd}$, the increase in sodium absorption and in potassium secretion, together with the blocking of these effects by spironolactone, are all characteristic (Levitan and Ingelfinger, 1965; Shields et al, 1966; Richards, 1969; Edmonds, 1972). The rise in pd occurred in all of the individuals given the drug indicating that the mineralocorticoid action is not confined to those who have overt side effects. There are several ways in which this action might be produced by carbenoxolone and these are best considered in relation to the effects of aldosterone itself. Aldosterone appears to bind to a cytosol receptor and promote, through the DNA-RNA-ribosome system, the formation of specific proteins responsible for the changes in sodium and potassium transport (Edelman and Fimognari, 1968). One possibility is that carbenoxolone simply acts like aldosterone itself in this system, binding with the receptors and promoting the production of the specific proteins. Thus here carbenoxolone would be considered as a mineralocorticoid-type agent like 9- $\alpha$-fluorocortisol, for example, although apparently much weaker since on the basis of our findings, the latter is, on a weight basis, practically a thousandfold more potent than carbenoxolone. Alternatively, since carbenoxolone has strong affinity for serum and tissue proteins, it may produce its mineralocorticoid effects by displacing aldosterone from binding proteins thus allowing more free aldosterone to react with the specific receptor sites. From the present study, showing that carbenoxolone is effective in low dose when applied directly to the luminal side of rectal mucosa, it can be concluded that displacement of aldosterone from serum proteins by carbenoxolone is not responsible for this mineralocorticoid effect. However, other possibilities remain, for example, that carbenoxolone may displace aldosterone from non-specific protein-binding sites within the cells or affect aldosterone action at a cellular level.

All individuals taking carbenoxolone showed evidence of excessive mineralocorticoid activity as judged by the changes observed in the bowel mucosa. The pd remained elevated for as long as the carbenoxolone was taken, a finding similar to that observed during prolonged 9- $\alpha$-fluorocortisol administration and in patients with hyperaldosteronism (Edmonds and Richards, 1970). The bowel, unlike the kidney, does not 'escape' from the mineralocorticoid effects. In various pathological states and in some normal individuals, the renal 'escape' mechanism appears not to operate so that a continuing positive sodium balance leads to oedema formation. The pd measured in the one patient who developed considerable salt and water retention was not significantly different from values found in the other patients who had no side effects, suggesting that the active sodium absorption mechanism was under similar stimulation and that the development of fluid retention in that patient was the result of failure of renal 'escape'.

The studies made with diuretics showed that spironolactone could completely abolish the mineralocorticoid activity of carbenoxolone. Spironolactone should therefore be the ideal agent in preventing side effects but unfortunately it seems also to interfere with the efficacy of carbenoxolone in healing gastric ulcers (Doll, Langman, and Shawdon, 1968) and so cannot be used. Both the other diuretics used, one a thiazide drug, bendrofluazide, and the other, amiloride, did not affect the mineralocorticoid action of carbenoxolone on the bowel. Amiloride would be expected to be useful in preventing the side effects of carbenoxolone because it acts on the distal renal tubule to reduce sodium absorption and potassium secretion although it is not a competitor of mineralocorticoids (Baer, Mucha, Spitzer, and Yee, 1966). Therefore while it is a relatively weak diuretic, it does reduce potassium loss and so is valuable in avoiding hypokalaemia and total body potassium depletion when there is excessive mineralocorticoid activity, for example, in hyperaldosteronism or when carbenoxolone is used (Reynolds and Pelle, 1966; Alter, Cushman, and Hilton, 1967; Braren, Campbell, Hashim, and Van Hallie, 1968; Edmonds and Tomkins, 1975). Its influence on the healing properties of carbenoxolone has not been tested, but, since it is quite different from spironolactone in its mode of action, it seems unlikely that it would interfere with the therapeutic action of carbenoxolone.

In conclusion, it appears from this study that carbenoxolone consistently produces mineralocorticoid activity in the rectal mucosa of all individuals taking the drug. This action of carbenoxolone does not depend on displacement of aldosterone from serum proteins but may reflect an inherent mineralocorticoid property of carbenoxolone. This mineralocorticoid effect is antagonized by spironolactone but not by bendrofluazide or amiloride and the latter drug may be of value in treating fluid retention during carbenoxolone therapy because of its potassium-sparing action which is not due to aldosterone antagonism.

Our thanks are due to Miss Jennifer Mackenzie for her invaluable assistance in carrying out this study, and to Dr S. Gottfried, of Biorex Laboratories Ltd, for his help and for providing carbenoxolone for topical use. 


\section{References}

Alter, S., Cushman, P., and Hilton, J. G. (1967). A new guanidine diuretic, amipramizide: reduction of the kaliuretic effect of ethacrynic acid in man. Clin. Pharmacol., 8, 243-248.

Archampong, E. Q., and Edmonds, C. J. (1972). Effect of luminal ions on the transepithelial potential difference of human rectum. Gut, 13, 559-565.

Baer, J. E., Mucha, C. M., Spitzer, S. A., and Yee, H. W. A. (1966). A $\mathrm{K}^{+}$-sparing natriuretic pyrazinamide derivative. (Abstr.) Fed. Proc., 25, 197.

Baron, J. H., and Nabarro, J. D. N. (1968). Metabolic studies of carbenoxolone sodium as biogastrone or duogastrone in patients with peptic ulcer. In $A$ Symposium on Carbenoxolone Sodium, edited by J. M. Robson and F. M. Sullivan, pp. 127 157. Butterworths, London.

Beevers, D. G. (1973). Mineralocorticoids and rectal potential difference. Lancet, 2, 682-683.

Borst, J. G. G., ten Holt, S. P., de Vries, L. A., and Molhuysen, J. A. (1953). Synergistic action of liquorice and cortisone in Addison's and Simmond's disease. Lancet, 1, 657-663.

Braren, C. H., Campbell, R. G., Hashim, S. A., and van Itallie, T. B. (1968). Use of amiloride in preoperative management of a patient with primary aldosteronism. Amer.J. Med., 45, 480-484.

Cooperstein, I. L., and Hogben, C. A. M. (1959). Ionic transfer across the isolated frog large intestine. J. gen. Physiol., 42, 461-473.

Doll, R., Hill, I. D., Hutton, C., and Underwood, D. J. (1962). Clinical trial of a triterpenoid liquorice compound in gastric and duodenal ulcer. Lancet, 2, 793-796.

Doll, R., Langman, M. J. S., and Shawdon, H. H. (1968). Treatment of gastric ulcer with carbenoxolone: antagonistic effect of spironolactone. Gut, 9, 42-45.

Edelman, I. S., and Fimognari, G. M. (1968). On the biochemical mechanism of action of aldosterone. Rec. Progr. horm. Res., 24, $1-44$.

Edmonds, C. J. (1971). Absorption of sodium and water by human rectum measured by a dialysis method. Gut, 12, 356-362.

Edmonds, C. J. (1972). Effect of aldosterone on mammalian intestine.
J. steroid Biochem., 3, 143-149.

Edmonds, C. J., and Godfrey, R. C. (1970). Measurement of electrical potentials of the human rectum and pelvic colon in normal and aldosterone-treated patients. Gut, 11, 330-337.

Edmonds, C. J., and Marriott, J. C. (1969). The effect of aldosterone on the electrical activity of rat colon. J. Endocr., 44, 363-377.

Edmonds, C. J., and Richards, P. (1970). Measurement of rectal electrical potential difference as an instant screening test for hyperaldosteronism. Lancet, 2, 624-627.

Edmonds, C. J., and Tomkins, A. M. (1975). Carbenoxolone effects on body potassium and the bowel. In Fourth Symposium on Carbenoxolone Sodium, edited by Sir Francis Avery Jones and D. V. Parke, pp. 129-150. Butterworths, London.

Efstratopoulos, A. D., Peart, W. S., and Wilson, G. A. (1974). The effect of aldosterone on colonic potential difference and renal electrolyte excretion in normal man. Clin. Sci., 46, 489-499.

Levitan, R., and Ingelfinger, F. J. (1965). Effect of d-aldosterone on salt and water absorption from the intact human colon. J. clin. Invest., 44, 801-808.

Mackay, N. (1968). Discussion to Wynn. In A Symposium on Carbenoxolone Sodium, edited by J. M. Robson and F. M. Sullivan, pp. 186-187. Butterworths,' London.

Reynolds, T. B., and Pelle, H. C. (1966). Effects of a new diuretic, amipramidine (MK870), in patients with cirrhosis and ascites. Clin. Res., 14, 262.

Richards, P. (1969). Clinical investigation of the effects of adrenal corticosteroid excess on the colon. Lancet, 1, 437-442.

Shields, R., Mulholland, A. T., and Elmslie, R. G. (1966). Action of aldosterone upon the intestinal transport of potassium, sodium and water. Gut, 7, 686-696.

Wrong, O. M., Metcalfe-Gibson, A., Morrison, R. B. I., Ng, S. T. and Howard, A. V. (1965). In vivo dialysis of faeces as a method of stool analysis. I. Techniques and results in normal subjects. Clin. Sci., 28, 357-375.

Wynn, V. (1968). Metabolic effects of carbenoxolone sodium administration in man. In A Symposium on Carbenoxolone Sodium edited by J. M. Robson and F. M. Sullivan, pp. 173-194 Butterworths, London. 